Article

\title{
Effects of Adding Batteries in Household Installations: Savings, Efficiency and Emissions
}

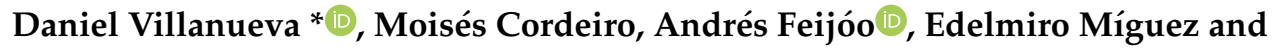 \\ Antonio Fernández \\ Electrical Engineering Department, University of Vigo, Rúa Maxwell s/n, 36310 Vigo, Spain; \\ moises.cordeiro.costas@uvigo.es (M.C.); afeijoo@uvigo.gal (A.F.); edelmiro@uvigo.es (E.M.); \\ afotero@uvigo.es (A.F.) \\ * Correspondence: dvillanueva@uvigo.es; Tel.: +34-9-8681-8745
}

Received: 3 July 2020; Accepted: 13 August 2020; Published: 25 August 2020

check for updates

\begin{abstract}
Nowadays, common electrical household appliances are mostly being powered by means of alternate current (AC), although there are cases where direct current (DC) is used instead. In all cases, internal devices are supplied with DC, and this fact involves there are losses due to the need for AC/DC converters. At the same time, most electrical home consumption takes place during peak hours when electricity is more expensive in many electricity markets. The addition of a battery in these installations permits storing electrical energy during certain periods of the day with the aim of supplying it during other ones-when this operation is more efficient or convenient-simultaneously reducing costs and greenhouse gas emissions. In this paper, a comparison is proposed between three possible home consumption scenarios, i.e., one consisting of a current AC system, one consisting of an AC system with a battery, and a third consisting of a hybrid AC/DC system with a battery.
\end{abstract}

Keywords: battery storage; demand response; electrical power systems; electricity consumption; energy cost; energy efficiency; load profile; residential building

\section{Introduction}

Most of electrical appliances used in private homes nowadays operate with AC supply, mainly due to its availability. However, there are others that need to be powered with DC, such as certain facilities located in remote places, ships or campervans and also appliances such as fridge-freezers, extractor hoods, microwave ovens or coffee machines. From the point of view of their internal architectures, most home appliances need to be supplied with DC. For instance, televisions, routers or other electronic devices. The presence of this type of domestic equipment increases with the progress of technology, involving losses due to the need of AC/DC conversion [1-6].

The consumption of electricity by household appliances has an increasing trend. First, electric cookers have been gradually substituting gas ones. Second, for heating and cooling, heat pumps are also increasing their share percentage. Moreover, the growing dependency on phones, tablets and any other kind of battery charging devices gives rise to a proliferation of plug-load devices. Moreover, resident preferences such as large screens, high resolution ones or the need for Internet connectivity creates a large electricity demand of commonly connected devices [7-10].

The most efficient AC appliances on the market are expensive. The prices of AC devices are lower than the prices of their equivalent DC models, mainly due to the mass production of household appliances for AC uses. However, if both possibilities were evaluated under the same conditions, the prices of DC appliances could be similar to the prices of their AC versions-or even lower. In fact, due to their simplicity, DC electrical appliances need a lower quantity of components for their construction, making their cycle of life longer and having lower probability of failure [11-16]. 
Climate change is a fact. There is evidence that since industrial revolution, the climatic trends of our planet differ from the natural behavior previously produced on the Earth, such as shrinking ice sheets, global temperature and sea level rising or extreme events, among others [17]. In the Roadmap 2050 [18], the European Union (EU) has established some goals with the aim of reducing up to an $80 \%$ the greenhouse gas emissions by 2050 , with respect to 1990 . This requires emissions' reduction to take place in all sectors. Residential and commercial buildings consume a $40 \%$ of the total energy needs in the EU [19], being energy efficiency the key to achieve its objectives. Regarding household savings, the efficiency of each appliance is important to reduce the total demand, entailing a lower need of energy production and a reduction of emissions [20,21]. Furthermore, a large amount of household energy demand happens during peak hours, i.e., those when the electric price is higher, so the reduction in energy consumption leads to lower electricity costs [22-24].

Most electrical appliances such as smartphones-and nowadays, hybrid and electric vehicles-have a battery integrated that has had a huge importance in the development of the batteries. In this way, the advancement of technology has led to the optimization of batteries that involves a reduction of costs and an improvement of their properties. In turn, the fact of using a battery as a power source for electrical appliances provides security of supply against power outages for a certain period of time (depending on the level of charge at the moment when the fault occurs and the total capacity of the battery) [25-27].

The installation of a battery makes it possible to accumulate energy in the most suitable periods and to supply this stored energy throughout the rest of the day, allowing one to optimize consumption and to reduce, in turn, the electricity bill. In [28] a mathematical model was developed to find optimal schedules for an energy management system used in a home where energy prices and generation from renewable sources are time-varying, integrating storage devices and electric vehicles. In [29] a learning algorithm has been modeled to adapt the control policies for the household energy storage systems combining with the use of electric vehicles and heating, ventilating and air conditioning systems. In [30] an optimal sizing and energy management system has been developed to add a battery energy storage system and a photovoltaic power generation to maximize the home economy. In [31] a reduction of the power consumption is elaborated within the household by adapting DC appliances using a battery and a photovoltaic system. In [32] an energy management system for residential demand response is proposed using reinforced learning and fuzzy reasoning. In [33] a particle swarm optimization algorithm is proposed to schedule the household appliances in the off-grid energy system (photovoltaic, wind turbine, batteries and diesel generator) with the objective of saving energy and reducing the energy consumption cost. In [34] a multi objective optimization model is designed to minimize the electricity costs for the homeowner as well as the $\mathrm{CO}_{2}$ emissions from the operation of a battery energy storage system under dynamic prices. In [35] a performance of a small household scale battery energy system with a lithium-ion battery pack and a single-phase DC/AC inverter.

It is possible to charge the battery directly from the electrical network. However, there are some alternatives to this. In this paper, some possibilities are commented regarding the use of the workout devices and the electric vehicle. With workout devices, one type of environmentally friendly power plant can be obtained, consisting of a generator which is harnessing human-generated energy when exercising [36,37], being important to recognize energy expenditure during activity with physical tests [38] or using electronic devices, i.e., smart watches [39]. On the other hand, to achieve the emissions' reduction objectives, the EU establishes, in Roadmap 2050 [18], that the impact of combustion cars will decrease slightly until 2030 and, in the 2040 decade, there will be a significant replacement. In turn, it is important to optimize the house-electric vehicle connection to manage the energy demand $[40,41]$ in the near future.

This paper is organized as follows: Section 2 presents a description of the three analyzed systems; a description of household battery types is introduced and a discussion is included about how they can affect greenhouse gas emissions as well as some possible improvements for these systems. A specific case is shown in Section 3; the mathematical model employed for the resolution of the discussed 
scenarios is explained in Section 4; a simulation of the specific case is presented in Section 5; the results are discussed in Section 6 and the conclusions are outlined in Section 7.

\section{Proposal}

The analysis proposed in this paper focuses on the way different systems affect domestic demand. The possibilities of installing batteries and connecting household appliances by using either AC or DC power are evaluated. As commented above, energy efficiency at homes is a very important issue for achieving objectives related to greenhouse gas emissions reduction.

Therefore, the impact of the assessed possibilities is studied. Finally, some alternatives to charge batteries are introduced, such as the use of the energy produced by workout activities and by the batteries of electric vehicles.

\subsection{Considered Scenarios}

Household supply systems are currently connected directly to the electrical network. Therefore, electrical appliances are supplied with AC and domestic demand depends on how these appliances are being used. Most of this demand occurs during peak hours when the electricity prices are higher. The use of a battery at home opens the opportunity to offer an adapted demand response, where a higher cost-effectiveness can be attained. Therefore, a modification is proposed in this study with the purpose of reducing the costs, which combines the current system with the use of a battery. However, as a battery needs an AC/DC converter for interacting with the electrical power system, this involves lower operating efficiency. Consequently, as mentioned, a new system is here proposed, where the electrical appliances are fed with DC in combination with a battery, with the consequence of discarding the losses in each appliance and in the battery output.

As aforementioned, a comparison is presented here, assuming identical operating conditions, among three possible modes, i.e., (a) a conventional system with AC appliances and direct connection to the electrical network, (b) an AC system with AC appliances and a battery installed and (c) a combined AC/DC system with DC appliances and direct connection to the battery. The proposed models are shown in Figure 1.

a)

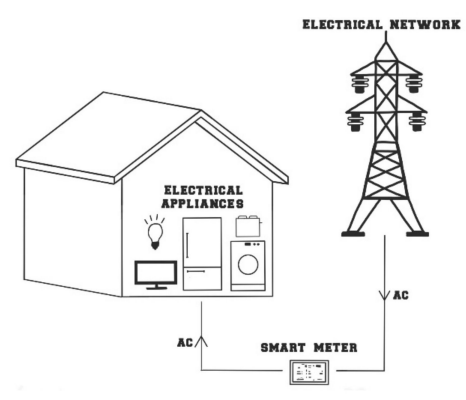

b)

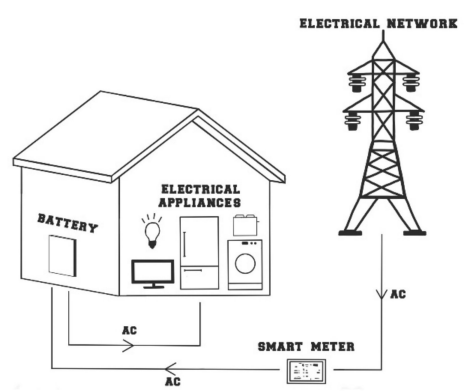

c)

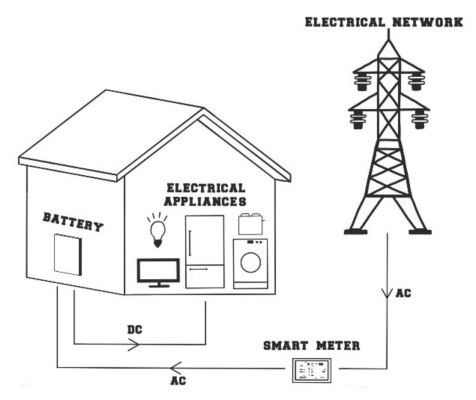

Figure 1. Simplified architecture of the proposed models: (a) Current AC system. (b) AC system with battery. (c) Combined AC/DC system with battery. 
In Table 1, the electrical appliances considered in the study are shown, classified per application in eight types [12]. The efficiencies in all the appliances have been established and the elements where standby is present have been pointed out.

Table 1. Electrical appliances with their conversion efficiencies divided by groups.

\begin{tabular}{|c|c|c|}
\hline Group & Electrical Appliance & AC-DC Conversion Eficiency \\
\hline COLD & Fridge-freezer & 0.87 \\
\hline LIGHTING & Lighting & 0.82 \\
\hline \multirow{3}{*}{ WASHING AND DRYING } & Dishwasher & 0.88 \\
\hline & Washing machine & 0.87 \\
\hline & Clothes dryer & 0.89 \\
\hline \multirow{7}{*}{ ICT } & Router* & 0.85 \\
\hline & Multifunction printer * & 0.8 \\
\hline & Laptop * & 0.8 \\
\hline & Desktop * & 0.8 \\
\hline & Monitor * & 0.85 \\
\hline & Speakers & 0.79 \\
\hline & Telephone * & 0.8 \\
\hline \multirow{4}{*}{ AUDIOVISUAL } & Radio * & 0.79 \\
\hline & Game console * & 0.8 \\
\hline & Set-top box* & 0.85 \\
\hline & Plasma TV * & 0.85 \\
\hline \multirow{7}{*}{ COOKING } & Coffee machine * & 0.87 \\
\hline & Toaster & 0.88 \\
\hline & Extractor hood & 0.88 \\
\hline & Food mixer & 0.88 \\
\hline & Oven & 0.88 \\
\hline & Electric cooker & 0.88 \\
\hline & Microwave & 0.87 \\
\hline \multirow{4}{*}{ HEATING AND COOLING } & Air conditioning & 0.89 \\
\hline & Circulation pump & 0.88 \\
\hline & Water heating & 0.88 \\
\hline & Heating & 0.88 \\
\hline \multirow{8}{*}{ OTHER } & Charger & 0.8 \\
\hline & Dehumidifier & 0.87 \\
\hline & Doorbell & 0.87 \\
\hline & Hair dryer & 0.87 \\
\hline & Hair straightener & 0.87 \\
\hline & House alarm & 0.83 \\
\hline & Iron & 0.87 \\
\hline & Vacuum cleaner & 0.87 \\
\hline
\end{tabular}

${ }^{*}$ standby consideration.

\subsection{Batteries}

It is important to select the most suitable battery for the installation. This involves selecting the correct characteristics in order to satisfy the demand. In addition, it is necessary to know the possibilities offered by batteries existing in the market. The types that can be installed at home are usually divided into 3 groups, namely, monoblock, stationary and lithium batteries.

Monoblock batteries are used in small installations with reduced demand. They can supply a large amount of energy in short periods of time. Their useful life is 5 years for depths of discharge of $50 \%$ and their price is the lowest one among all batteries.

Stationary batteries are used in homes with a continuous demand and medium to high consumption with peaks of demand and moderate discharge. They are composed of $2-\mathrm{V}$ blocks interconnected to 
obtain the necessary voltage, requiring large spaces for their installation. Their useful life is 15 years for depths of discharge of $50 \%$ and their price is moderate.

Lithium batteries can be used in any type of installation due to their versatility. They have no memory effect and can be rapidly charged and discharged. Their useful life is 20 years for depths of discharge of $80 \%$ and their price is the higher.

Both monoblock and stationary types are lead-acid batteries. These can be sealed or opened-and in the case of opened ones, when an annual maintenance is necessary. However, lithium batteries do not need any maintenance.

Lithium batteries have three times higher energy density than lead ones. This means that a smaller size of them provides the same amount of energy. In addition, lithium batteries have a higher oxidation capacity than lead ones, resulting in a voltage level of $3.12 \mathrm{~V}$ and $2 \mathrm{~V}$, respectively. This makes lithium batteries more efficient than lead batteries [42,43].

\subsection{Emissions}

Energy generation entails greenhouse gas emissions. The available energy is not only obtained from renewable sources. On the contrary, conventional sources are present in the energy mix. Among them, thermal power plants are, in many electricity markets, the basis for power generation. Consequently, there are large quantities of greenhouse gas emissions due to household consumption.

As long as the percentage of renewable energy used in the energy mix is increased, greenhouse gas emissions will be lower. One way to optimize the renewable energy production is to store the energy in periods of time during which it is available, but not demanded. This process can be performed by using storage means, such as batteries.

As aforementioned, most electrical home appliances are powered with DC, involving losses in each appliance due to the need for AC/DC conversion. By means of an AC/DC combined system, the $\mathrm{AC}$ is converted into $\mathrm{DC}$ and stored in the battery, and then, electrical appliances are powered directly with DC from the battery, which contributes to reduce the household losses.

The reduction of energy consumption and the optimization of the renewable energy sources imply a lower generation of energy and, consequently, according to the average value of European $\mathrm{CO}_{2}$-emission-intensity levels [20], there is a reduction in greenhouse gas emissions.

\subsection{Energy Generated by Workout Activities}

A possible step to encourage personal well-being is to promote electricity generation with workout machines that have been proliferating in private homes, such as cardio devices, treadmills or bicycles $[36,37]$. There is a considerable variety of factors that can influence the energy contribution of a person who is exercising, such as age, weight, intensity or activity time. The World Health Organization (WHO) recommends people to walk around 10,000 steps throughout the day [44] —and due to the current movement habits of many people-this only requires walking quickly during one hour, which is an accessible exercise for everybody.

To take into account the possibilities of cardio devices, it has been considered that it is possible to use the mechanical energy produced on certain parts of them, so when running or walking on treadmills, a force is generated at each stride that produces the movement of the belt and, when pedaling on bicycle, a rotatory movement is induced to the hub. In order to take advantage of this energy, the cardio device must be connected to an electric machine that charges the battery.

The possibility that cardio devices offer consists of supplying energy to a battery or to any appliance that can be in operation during the period of exercising, by reducing the energy necessities from the electrical network, entailing clean energy generation and a reduction of electricity costs. This possibility has not been evaluated in this paper, as it is now being in development for future versions. 


\subsection{Electric Vehicle}

As commented earlier, nowadays the number of electric vehicles on the roads is increasing, and therefore, one way to provide support to the battery at the required moment is to establish a connection between the household battery and the battery of the electric vehicle [40,41]. Focus must be put on the fact that, when users are at home, the electricity consumption is higher and, in those moments, there is energy available at the electric vehicle. This connection can provide power support in the house when needed, reducing household demand. However, the battery of the electric vehicle must assure at least a daily use, so a minimum value must be preserved. On the other hand, if necessary, the electric vehicle can also be charged. In this paper, the possibilities provided by the electric vehicle are not assessed, and its implementation will be the subject of future research.

\section{Problem Formulation}

The associated energy management problem is formulated along the time horizon $T$ with several time intervals employing Equations (1)-(8). An hourly time-step $(\delta t)$ for a period of one year is considered.

In each time step the systems must satisfy the power balance between consumption and production and this can be expressed by means of (1):

$$
P_{E N}(t)+P_{D i s c h}(t)=\sum_{j} D_{E A}(t, j)+P_{C h}(t)
$$

where $P_{E N}(t)$ is the power consumed from the electrical network in $t, P_{D i s c h}(t)$ is the power discharged from the battery, i.e., obtained from it, during the period $t, D_{E A}(t, j)$ is the demand of each electrical appliance $j$ in $t$ and $P_{C h}(t)$ is the charging power of the battery in $t$.

As can be expected, for the current AC system, the whole household demand is supplied from the electrical network. On the other hand, the battery involves a certain level of energy, so it is important to recognize the energy stored in the battery in $t, E_{B}(t)$, expressed in (2):

$$
E_{B}(t)=C_{n o m} \cdot S O C(t-1)+\eta_{C h} \cdot P_{C h}(t) \cdot \delta t-\frac{P_{D i s c h}(t) \cdot \delta t}{\eta_{\text {Disch }}}
$$

where $C_{n o m}$ is the nominal capacity, $\operatorname{SOC}(t-1)$ is the state of charge in the previous period $(t-1), \eta_{C h}$ is the charging efficiency and $\eta_{\text {Disch }}$ is the discharging efficiency.

There are limitations linked to battery technical characteristics. The boundaries proposed for the maximum and minimum energy stored are defined in (3) and (4).

$$
\begin{gathered}
C_{n o m} \cdot \operatorname{SOC}(t-1)+\eta_{C h} \cdot P_{C h}(t) \cdot \delta t \leq C_{\text {nom }} \\
C_{\text {nom }} \cdot \operatorname{SOC}(t-1)-\frac{P_{\text {Disch }}(t) \cdot \delta t}{\eta_{\text {Disch }}} \geq C_{\text {nom }} \cdot E_{\text {min }}
\end{gathered}
$$

where $E_{\min }$ is the minimum percentage of energy allowed in the battery. This parameter is defined to protect the battery from a full discharge.

On the other hand, the charging and discharging processes are shown in Equations (5)-(7):

$$
P_{C h}(t) \leq P_{C h, \max } \cdot Q
$$

where $P_{C h, \max }$ is the maximum charging power and $Q$ is a Boolean variable that allows the system to know whether the battery should be charged:

$$
Q=\left\{\begin{array}{l}
0, \text { if } t \in[\text { peak hours }] \text { and } E_{B}>C_{\text {nom }} \cdot E_{\text {min }} \\
1, \text { if } t \notin[\text { peak hours }] \text { or } E_{B} \equiv C_{\text {nom }} \cdot E_{\text {min }}
\end{array}\right.
$$




$$
P_{\text {Disch }}(t) \leq P_{\text {Disch, } \max }
$$

where $P_{D i s c h, \max }$ is the maximum discharging power.

The objective function aims to minimize the electricity bill of the residential building. This is the one defined in Equation (8):

$$
f=\sum_{t=1}^{T}\left[P_{E N}(t) \cdot \delta t \cdot C_{E N}(t)\right]
$$

where $C_{E N}(t)$ are the electricity costs in $t$.

\section{Case Study}

The average demand data for electrical appliances in the United Kingdom collected by Intertek was selected [1]. The case considered is a house inhabited by a family with children; a moderate use of electrical appliances was assumed, with an installed power of $4.6 \mathrm{~kW}$.

Electrical appliances were evaluated under the same conditions, so the prices of AC devices were considered to be the same as those of the equivalent models in DC. It has also been considered that DC voltage levels tend to a constant value, due to technological trends.

A lithium battery was selected in order to optimize its use, since it covers the household energy demand, allows high depth of discharge with high efficiency and does not need much space. The characteristics of the battery used in the study are those of the Tesla Powerwall [45]. The capacity is $13,500 \mathrm{Wh}$, the maximum discharging and charging powers are 7000 and $5000 \mathrm{~W}$ for $\mathrm{AC}$ and DC respectively and the efficiency in the complete cycle is $90 \%$.

The differences in energy demand in different months were obtained from Red Eléctrica de España (REE) data [23]. It was established that the habits in the house are different on working days (from Monday to Friday) and non-working days (Saturday and Sunday). The following days were considered as holidays: 1 January, 6 January, 13 April, 1 May, 31 May, 1 June, 15 August, 1 November and 25 December.

Winter and summer schedules were also distinguished; the time change was set according to official time change dates, i.e., 31 March and 27 October. In order to determine the costs, Iberdrola's Plan Noche-a charging system proposed by that company-was chosen [22]. Consequently, a time discrimination price was established with a fixed term of $45 € / \mathrm{kW}$ per year and where peak hours' cost is $0.183101 € / \mathrm{kWh}$ and off-peak hours' cost is $0.091863 € / \mathrm{kWh}$. Following Spanish standards, peak hours in the summer period are from 1 p.m. to 11 p.m. and in the winter period, from 12 p.m. to 10 p.m., being the off-peak hours the supplementary hours for each period.

For the comparison of greenhouse gas emissions in both cases, the average European $\mathrm{CO}_{2}$-emission-intensity levels in the EEA [20] were used.

\section{Data Analysis}

Data analysis was performed by means of different simulations of an iterative algorithm by using MATLAB and representing the year 2020 with the data presented in previous sections. The goal is to determine the differences between the systems presented in this study, comparing their efficiencies, emissions and the associated annual costs. In systems with battery, the initial load percentage is $40 \%$. With the aim of protecting the battery, when the charging status is below a $20 \%$, regardless whether this percentage was reached in peak or off-peak hours, it is mandatory that the battery starts charging. On the other hand, in order to maximize the effectiveness, it is considered a time discrimination period according to Spanish standards where, due to the presence of the battery, it is possible to accumulate energy in off-peak hours, being this energy consumed later during peak hours. In the following paragraphs, the methodology used in the algorithm to obtain the results is presented. Then, this section is divided as follows: first, the energy demand throughout the year is compared, then the battery systems in several days of the year are analyzed. and finally, the electricity costs in various months are shown. 
In order to obtain the efficiency of each system, the AC/DC conversion was taken into account. The electrical appliances in the current AC system are connected directly to the electrical network, so the losses are produced in each electrical device. Similarly, in the AC system with a battery, losses appear in the household appliances due to their AC connection-as well as due to the storage possibilities in the battery input and output. The domestic appliances in the AC/DC system with battery are powered directly by DC from the battery output, so, in this case, they were just considered losses in the battery input.

The emissions produced in the house for the evaluated systems were calculated using the calculations of household demand from the electrical network obtained with Equation (1) and $\mathrm{CO}_{2}$-emission-intensity levels [20].

In the same way as in the previous case, once the household demand is obtained from the electrical network and, by relating each period of time with the hourly costs, the variable costs were calculated. Then, adding the fixed costs related to the power factor, the annual electric costs of each system were determined.

\subsection{Energy Demand}

The total energy demand in the battery systems has the same pattern as in the current AC system because the activities during the day are not modified. However, there is a reduction of losses in each electrical appliance when it is supplied with DC because there is no need of power inversion from the battery $(-9.12 \%)$. This can be seen in Figure $2 \mathrm{a}$,c. Therefore, the energy demand throughout the year is lower in the combined AC/DC system with battery than in the current AC system due to the reduction of losses. On the other hand, the AC system with battery operates with more losses due to the need of converting the current between the battery and the network or the loads $(10.80 \%)$. As can be seen in Figure 2a,b, energy demand is higher than in the current AC system.
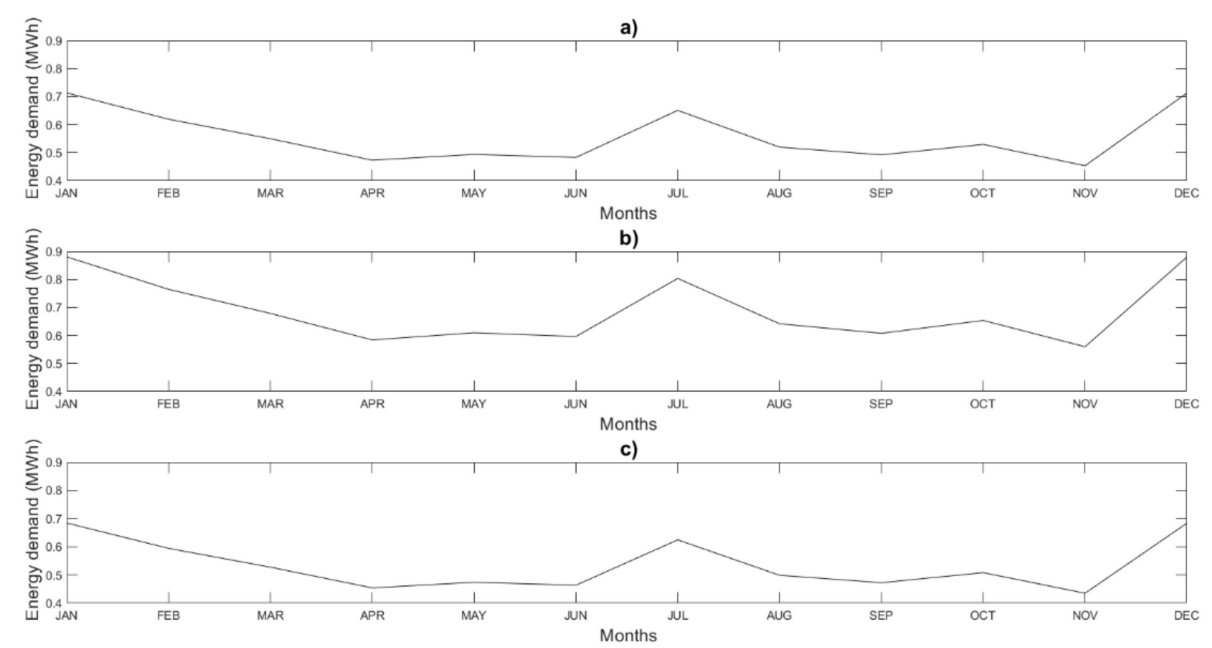

Figure 2. Energy demand during the year for each system: (a) Current AC system. (b) AC system with battery. (c) Combined AC/DC system with battery.

\subsection{Analysis of Battery Systems}

It is necessary to select the right battery for the proposed system, as this should satisfy the household demand throughout the day with the given requirements, avoiding over and undersizing. The maximum discharge power is higher than the household demand at any step of time, the battery capacity is used almost completely, and the system allows the use of the stored energy in peak hours while in off-peak hours it is loaded according to the necessities. Consequently, it can be accepted that the selected battery is the right one. 
The charging curve was evaluated in different days of the year. Figure 3 shows the curves corresponding to a winter day, 16th December and a summer day, 17th June, both of them Wednesdays.

As can be seen in Figure $3 a, c$, for the summer day in both systems, from 1 p.m. to 11 p.m., the battery is permanently discharged. Off-peak hours commence at 11 p.m., when the battery starts to charge up to the maximum.

As can be seen in Figure 3b, for the winter day in the AC system, from 12 p.m. to 8 p.m., the battery is permanently discharged. However, peak hours in winter go from 12 p.m. to 10 p.m. As can be seen, the battery is charged at full power regardless of the period because the charge at 8 p.m. is below a $20 \%$. The battery is discharged again at 9 p.m., because it is still during peak hours. When off-peak hours begin, at 10 p.m., the battery starts to charge again up to its maximum.

As can be seen in Figure 3d, for the winter day in the combined AC/DC system, from 12 p.m. to 10 p.m., the battery is permanently discharged. Off-peak hours commence at 10 p.m., so the battery starts to charge until full capacity is reached.

In all cases, due to the demand along the hours, the maximum level of battery charge depends on the demand at each moment, establishing an almost constant maximum charge in off-peak hours.
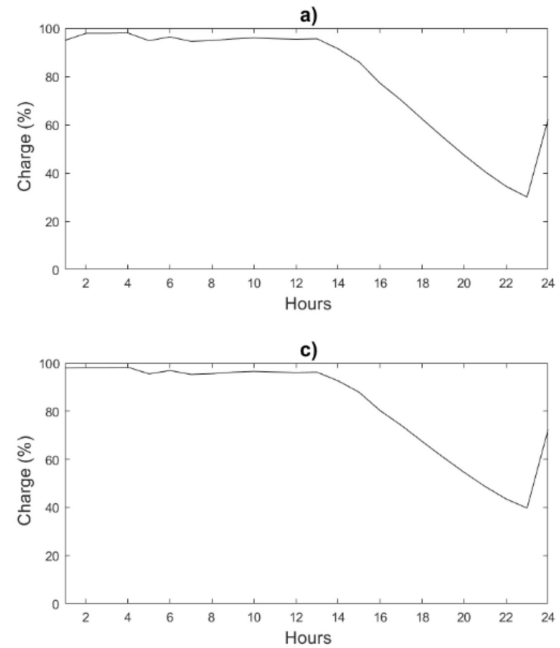

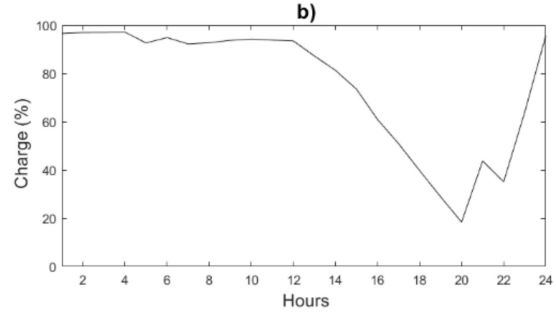

d)

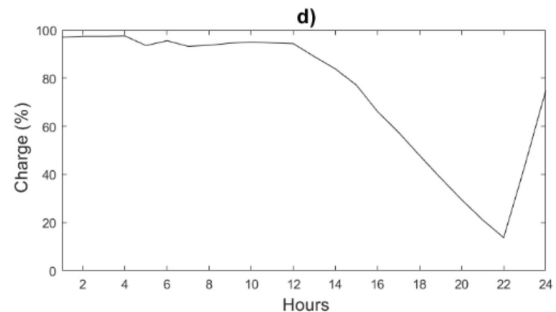

Figure 3. Charging cycle for specific days of the year for the battery-powered systems: (a) AC system on 17 June. (b) AC system on 16 December. (c) Combined AC/DC system on 17 June. (d) Combined AC/DC system on 16 December.

\subsection{Electricity Costs}

The evaluation of the charging curve was established in December and June. Figure 4 shows the total costs of these months along the day.

Due to the absence of battery (Figure $4 a, b$ ) the electrical network supplies the household demand along both months by means of the AC system.

In both systems with battery in June, Figure $4 \mathrm{c}, \mathrm{e}$, the charge levels are similar to the demand produced during those months. As a consequence, when the battery is discharging, the costs are $0 €$ and an overcost is produced because of the charging process to recover the maximum. The costs in the combined AC/DC system begin to be due to the household demand at 2 a.m. On the contrary, the AC system starts at 3 a.m. This difference is due to the lower losses in the AC/DC system.

In the AC system with battery in December, Figure $4 \mathrm{~d}$, as seen before, the costs are $0 €$ when the battery is discharged and an overcost arises when the maximum charging level must be recovered. The percentage of charge is lower than $20 \%$ at 8 p.m., so the battery must be charged. The costs at 10 p.m. are $0 €$, due to the charge during the previous hour and because it still happens during peak hours. Off-peak hours commence at 10 p.m., so the battery must charge; this produces an overcost. Finally, the costs begin to be due to the household demand at 2 a.m. 
In the combined AC/DC system with battery in December, Figure $4 \mathrm{f}$, as seen before, the costs are 0 $€$ when the battery is discharged and an overcost is produced to recover the maximum charging level. The percentage of charge in the battery at 9 p.m. is lower than $20 \%$, so the battery must be charged. The off-peak hours start at 10 p.m., so the battery continues charging. Finally, the costs begin to be due to the household demand at 2 a.m.

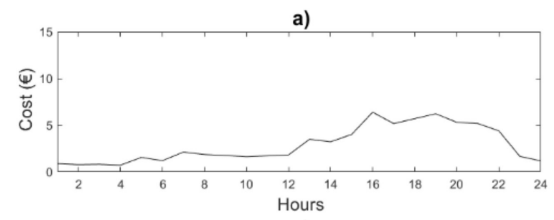

c)

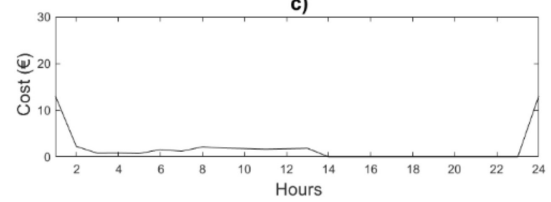

e)

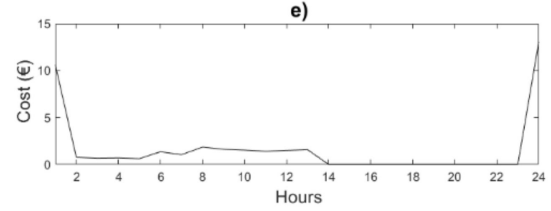

b)

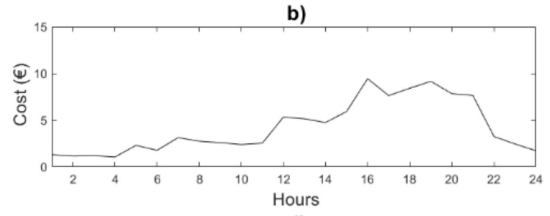

d)

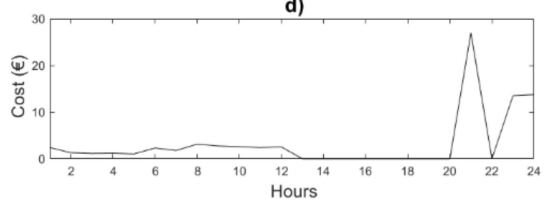

f)

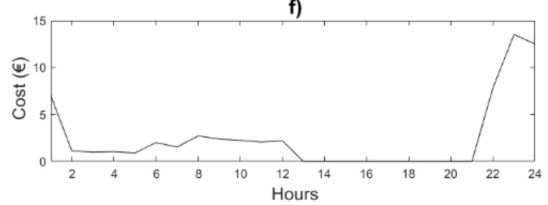

Figure 4. Total electricity costs for specific months of the year, by hours, for each system: (a) Current AC system on June. (b) Current AC system on December. (c) AC system with battery on June. (d) AC system with battery on December. (e) Combined AC/DC system with battery on June. (f) Combined AC/DC system with battery on December.

\section{Results}

The values of savings, efficiency and emissions were calculated in the simulations for each system. The results were summarized in Table 2. The payback was calculated with the initial costs, i.e., cost of the battery used ( $8240 €$ ) [45] and cost of the installation (1000 $€$ ) [46] and also by considering the mean European inflation rate $(1.97 \%)$ [47].

Table 2. Comparison of the systems evaluated.

\begin{tabular}{cccc}
\hline & $\begin{array}{c}\text { Combined AC/DC System } \\
\text { with Battery Respect to } \\
\text { Current AC System }\end{array}$ & $\begin{array}{c}\text { AC System with } \\
\text { Battery Respect to } \\
\text { Current AC System }\end{array}$ & $\begin{array}{c}\text { Combined AC/DC System } \\
\text { Respect to AC System } \\
\text { (Both with Battery) }\end{array}$ \\
\hline Savings (€/year) & 412.75 & 283.10 & 129.65 \\
Efficiency (\%) & 9.12 & -10.80 & 19.93 \\
Emissions ( $\mathrm{t}_{\text {CO2 } / \text { year) }}$ & -0.18 & 0.21 & -0.39 \\
Payback (years) & 17.73 & 24.45 & -6.72 \\
\hline
\end{tabular}

Energy demand in the combined AC/DC system with battery is lower than in the current AC system, resulting in lower annual household electricity costs $(-412.75 €)$. As there is no need of current conversion, the efficiency is higher (9.12\%) and due to this, greenhouse gas emissions are lower $\left(-0.18 \mathrm{t}_{\mathrm{CO} 2}\right)$.

On the other hand, energy demand in the AC system combined with a battery is higher than in the current AC system, due to the need of current conversion at the connection point of the battery, which causes lower efficiency $(-10.80 \%)$ and higher greenhouse gas emissions. Nevertheless, due to the addition of the battery, annual electricity costs decrease $(-283.10 €)$.

Comparing both of the systems that include a battery, it can be determined that the combined AC/DC system can operate with lower losses than the AC system (-19.93\%), resulting in lower 
greenhouse gas emissions $\left(-0.39 \mathrm{t}_{\mathrm{CO} 2}\right)$. Both systems have annual electricity savings, but those of the AC/DC system are greater $(129.65 €)$.

The payback period was calculated in battery systems, resulting in 17 years and 9 months for AC/DC system and 24 years and 5 months for AC system.

\section{Conclusions}

Three electrical systems for household uses are analyzed and compared considering their efficiencies, savings, greenhouse gas emissions and the possibility of combine them with other recharge systems. The first one is constituted by a hybrid AC/DC system with a battery, the second one is just an AC/AC system with a battery and the last one is the classic AC system without any accumulation device, i.e., direct use of AC power. The comparison is performed without modifying household habits.

According to the case analyzed, the highest efficiency and the best savings are obtained with the AC/DC system due to the reduction of losses, because the inverse transformation is avoided (efficiency $9.12 \%$ higher) and due to the optimization of the consumption (i.e., the battery is charged during the low prices period (savings of $412.75 €$ )). The AC/AC system keeps this last feature (savings of $283.10 €$ ), but needs the inverse transformation of power, therefore it misses the main advantage of the AC/DC system (efficiency $10.80 \%$ lower). Even though both systems outperform the classic AC one, the AC/DC system is strongly recommended due to its efficiency and reduction of costs. Moreover, the systems based on batteries have the advantage of being independent of tariffs based on prices-by-periods.

On the other hand, greenhouse gas emissions in the combined AC/DC system are lower $\left(-0.18 \mathrm{t}_{\mathrm{CO} 2}\right)$ than those of the other two existing systems. In fact, when considering this feature, the AC/AC system is the one with the worst performance $\left(+0.21 \mathrm{t}_{\mathrm{CO} 2}\right)$. Therefore, again the AC/DC system outperform the other two systems.

Finally, when considering alternative or complementary options for recharge, the use of workout machines reduce the costs and the external consumption of energy and, its combination with a battery can help adjust the full process. Moreover, electric vehicles can also help supplying power to the system during peak periods as a back-up battery. In both cases, the use of systems with batteries is essential to obtain the highest efficiency.

Author Contributions: Data curation, M.C.; Formal analysis, D.V. and M.C.; Investigation, M.C.; Methodology, D.V. and M.C.; Project administration, D.V. and A.F. (Antonio Fernández); Resources, D.V., E.M and A.F. (Antonio Fernández); Software, M.C.; Supervision, D.V., A.F. (Andrés Feijóo) and E.M.; Validation, D.V., A.F. (Andrés Feijóo) and E.M.; Visualization, A.F. (Andrés Feijóo); Writing—original draft, M.C.; Writing—review \& editing, D.V. and A.F. (Andrés Feijóo). All authors have read and agreed to the published version of the manuscript.

Funding: This research received no external funding,

Conflicts of Interest: The authors declare no conflict of interest

\section{References}

1. Zimmermann, J.P.; Evans, M.; Griggs, M.; King, N.; Harding, L.; Roberts, P.; Evans, C. Household Electricity Survey. A Study of Domestic Electrical Product Usage; Intertek: Milton Keynes, UK, 2012; p. R66141.

2. Mohammad, A.; Asghar, S.B.; Ashraf, I. Mathematical modelling based demand response analysis of major household appliances. Int. J. Innov. Technol. Explor. Eng. 2019, 8, 3385-3392.

3. Stegner, C.; Glaß, O.; Beikircher, T. Comparing smart metered, residential power demand with standard load profiles. Sustain. Energy Grids Netw. 2019, 20, 100248. [CrossRef]

4. Xu, X.; Xiao, B.; Li, C.Z. Critical factors of electricity consumption in residential buildings: An analysis from the point of occupant characteristics view. J. Clean. Prod. 2020, 256, 120423. [CrossRef]

5. Vasseur, V.; Marique, A.F.; Udalov, V. A conceptual framework to understand households' energy consumption. Energies 2019, 12, 4250. [CrossRef]

6. Razak, M.A.; Yakub, F.; Sulaiman, N.N.I.; Ab Rashid, M.Z.; Shaikh Salim, S.A.Z.; Rasid, Z.A.; Abu, A. Energy consumption clustering analysis in residential building. In Proceedings of the SympoSIMM 2019, Melaka, Malaysia, 8 July 2019; pp. 436-450. 
7. Sayed, S.; Hussain, T.; Gastli, A.; Benammar, M. Design and realization of an open-source and modular smart meter. Energy Sci. Eng. 2019, 7, 1405-1422. [CrossRef]

8. Jebroni, Z.; Afonso, J.A.; Tidhaf, B. Smart home energy management system based on a hybrid wireless networkt architecture. EAI Endorsed Trans. Energy Web 2020, 7, 25. [CrossRef]

9. Appliances and Equipment. Available online: https://www.iea.org/reports/tracking-buildings/appliancesand-equipment (accessed on 15 July 2020).

10. Household Energy Consumption. Available online: https://www.eea.europa.eu/airs/2018/resource-efficiencyand-low-carbon-economy/household-energy-consumption (accessed on 15 July 2020).

11. Kamalakannan, D.; Mariappan, V.; Narayanan, V.; Ramanathan, N.S. Energy efficient appliances in a residential building. In Proceedings of the 2016 First International Conference on Sustainable Green Buildings and Communities (SGBC), Chennai, India, 18-20 December 2016.

12. Garbesi, K.; Vossos, V.; Shen, H. Catalogue of DC Appliances and Power Systems; Berkeley Lab: Berkeley, CA, USA, 2011.

13. Olk, H.; Mundt, J. Photovoltaics for Productive Use Applications. A Catalogue of DC-Appliances; Giz: Frankfurt, Germany, 2016.

14. Rodriguez Diaz, E.; Vasquez, J.C.; Guerrero, J.M. Intelligent DC homes in Future Sustainable Energy Systems: When efficiency and intelligence work together. IEEE Consum. Electron. Mag. 2016, 5, 74-80. [CrossRef]

15. Staples, J.; Martin, J.; Rajan, S. Standards for the introduction of accessible DC power in buildings. In Proceedings of the 2019 IEEE Symposium on Product Compliance Engineering (SPCE Austin), Austin, TX, USA, 11-12 November 2019.

16. Ogunleye, O.; Alabi, A.; Misra, S.; Adewumi, A.; Ahuja, R.; Damasevicius, R. Comparative study of the electrical energy consumption and cost for a residential building on fully ac loads vis-a-vis one on fully dc loads. In Proceedings of the ICDSSA 2019, New Delhi, India, 7-8 March 2019; pp. 395-405.

17. Climate Change: How Do We Know? Available online: https://climate.nasa.gov/evidence/ (accessed on 15 July 2020).

18. Directorate General for Energy. Energy Roadmap 2050; European Commission: Luxembourg, 2012.

19. $\mathrm{CO}_{2}$ Emission Intensity. Available online: https:/www.eea.europa.eu/data-and-maps/daviz/co2-emissionintensity-5\#tab-googlechartid_chart_11_filters=\%7B $\% 22$ rowFilters $\% 22 \% 3 \mathrm{~A} \% 7 \mathrm{~B} \% 7 \mathrm{D} \% 3 \mathrm{~B} \% 22$ columnFilters $\%$ 22\%3A \%7B \%22pre_config_ugeo $\% 22 \% 3 \mathrm{~A} \% 5 \mathrm{~B} \% 22$ European $\% 20$ Union $\% 20$ (current $\% 20$ composition) $\% 22 \%$ 5D\%7D\%7D (accessed on 15 July 2020).

20. Tragopoulos, G.; Sweatman, P. Challenges and Funding Opportunities for the Energy Efficient Renovation of Spain's Residential Building Stock; WWF: Madrid, Spain, 2012.

21. Setlhaolo, D.; Xia, X. Combined residential demand side management strategies with coordination and economic analysis. Int. J. Electr. Power Energy Syst. 2016, 79, 150-160. [CrossRef]

22. Plan Noche. Available online: https://www.iberdrola.es/luz/plan-noche (accessed on 15 July 2020).

23. Cómo Consumimos Electricidad. Available online: https://www.ree.es/sites/default/files/interactivos/como_ consumimos_electricidad/como-varia-mi-consumo.html (accessed on 15 July 2020).

24. Mazzeo, D.; Baglivo, C.; Matera, N.; Congedo, P.M.; Oliveti, G. A novel energy-economic-environmental multi-criteria decision-making in the optimization of a hybrid renewable system. Sustain. Cities Soc. 2020, 52, 101780. [CrossRef]

25. Uski, S.; Forssén, K.; Shemeikka, J. Sensitivity assessment of microgrid investment options to guarantee reliability of power supply in rural networks as an alternative to underground cabling. Energies 2018, 11, 2831. [CrossRef]

26. Hamdaoui, Y. A cyber-physical power distribution management system for smart buildings. In Proceedings of the Mediterranean Symposium on Smart City Applications, Tangier, Morocco, 25-27 October 2018; Volume 37, pp. 538-550.

27. Ghasemieh, H.; Haverkort, B.R.; Jongerden, M.R.; Remke, A. Energy Resilience Modelling for Smart Houses. In Proceedings of the International Conference on Dependable Systems and Networks, Goteborg, Sweden, 1-4 July 2001; pp. 275-286.

28. Merdanoğlu, H.; Yakici, E.; Doğan, O.T.; Duran, S.; Karatas, M. Finding optimal schedules in a home energy management system. Electr. Power Syst. Res. 2020, 182, 106229. [CrossRef]

29. Sun, Y.; Lampe, L.; Wong, V.W.S. Smart meter privacy: Exploiting the potential of household energy storage units. IEEE Internet Things J. 2018, 5, 69-78. [CrossRef] 
30. Wu, X.; Hu, X.; Yin, X.; Zhang, C.; Qian, S. Optimal battery sizing of smart home via convex programming. Energy 2017, 140, 444-453. [CrossRef]

31. Veerapaneni, S.; Palaniappan, K.; Cuzner, R.M. Analysis of solar and battery requirements for hybrid DC/AC powered households in the USA. Energy Effic. 2020, 13, 237-255. [CrossRef]

32. Alfaverh, F.; Denai, M.; Sun, Y. Demand response strategy based on reinforcement learning and fuzzy reasoning for home energy management. IEEE Access 2020, 8, 39310-39321. [CrossRef]

33. Bouakkaz, A.; Haddad, S.; Martín-García, J.A.; Gil-Mena, A.J.; Castañeda, R. Optimal scheduling of household appliances in off-grid hybrid energy system using PSO algorithm for energy saving. Int. J. Renew. Energy Res. 2019, 9, 427-436.

34. Olivieri, Z.T.; McConky, K. Optimization of residential battery energy storage system scheduling for cost and emissions reductions. Energy Build. 2020, 210, 109787. [CrossRef]

35. Bila, M.; Opathella, C.; Venkatesh, B. Grid connected performance of a household lithium-ion battery energy storage system. J. Energy Storage 2016, 6, 178-185. [CrossRef]

36. Prabowo, F.S.; Pangaribuan, P.; Darlis, D. Eco-electric generator system using human exercise activities. In Proceedings of the AASEC 2018, Bandung, Indonesia, 18 April 2018.

37. Ahsan Uz Zaman, K.M.; Ullah, K.M.; Mishir, M.; Alam, M. Generation of electrical power using gymnasium bicycle. In Proceedings of the 5th IEEE Region 10 Humanitarian Technology Conference, Dhaka Bangladesh, 21-23 December 2017; Volume 2018, pp. 198-200.

38. Li, S.; Xue, J.J.; Hong, P.; Song, C.; He, Z.H. Comparison of energy expenditure and substrate metabolism during overground and motorized treadmill running in Chinese middle-aged women. Sci. Rep. 2020, 10, 1-7. [CrossRef]

39. Cerezuela-Espejo, V.; Hernández-Belmonte, A.; Courel-Ibáñez, J.; Conesa-Ros, E.; Martínez-Cava, A.; Pallarés, J.G. Running power meters and theoretical models based on laws of physics: Effects of environments and running conditions. Physiol. Behav. 2020, 223, 112972. [CrossRef]

40. Cheng, P.H.; Huang, T.H.; Chien, Y.W.; Wu, C.L.; Tai, C.S.; Fu, L.C. Demand-side management in residential community realizing sharing economy with bidirectional PEV while additionally considering commercial area. Int. J. Electric. Power Energy Syst. 2020, 116, 105512. [CrossRef]

41. Nguyen, D.T.; Le, L.B. Joint optimization of electric vehicle and home energy scheduling considering user comfort preference. IEEE Trans. Smart Grid 2014, 5, 188-199. [CrossRef]

42. Divya, K.C.; Østergaard, J. Battery Energy Storage Technology for Power Systems-An Overview. Electric Power Syst. Res. 2009, 79, 511-520. [CrossRef]

43. The complete guide to lithium vs acid batteries. Available online: https://www.power-sonic (accessed on 15 July 2020).

44. Global Recommendations on Physical Activity for Health. Available online: https://www.who.int/ dietphysicalactivity/factsheet_recommendations/en/ (accessed on 15 July 2020).

45. Tesla PowerWall. Available online: https://www.tesla.com/es_ES/powerwall (accessed on 15 July 2020).

46. Everything You Need to Know About the Tesla Powerwall 2 (2020 Edition). Available online: https:/cleantechnica.com/2020/02/09/everything-you-need-to-know-about-the-powerwall-2-2019-edition/ (accessed on 15 July 2020).

47. Inflation Calculator-Euro. Available online: https://www.inflationtool.com/euro (accessed on 15 July 2020).

(C) 2020 by the authors. Licensee MDPI, Basel, Switzerland. This article is an open access article distributed under the terms and conditions of the Creative Commons Attribution (CC BY) license (http://creativecommons.org/licenses/by/4.0/). 